УдК 616.716.1-007.21-089.843

DOI 10.11603/2311-9624.2020.1.12033

\author{
(А. Іде ${ }^{1}$, С. Іде ${ }^{1}$, О. Сіпіч ${ }^{1}$, Я. Е. Варес ${ }^{2}$ І. Гомбкото ${ }^{1}$, Е. Сетураман ${ }^{1}$, Я. Я. Варес ${ }^{2}$ \\ Міжнародний фонд імплантологів, м. Мюнхен, Німеччина ${ }^{1}$ \\ Львівський національний медичний університет імені Данила Галицького ${ }^{2}$ \\ e-mail: vares-dent@ukr.net
}

\title{
Вимоги до тотальної протетичної реабілітації верхньої щелепи за технологією «Стратегічна імплантація» в умовах протоколу негайного навантаження (опис серії клінічних випадків)
}

\section{ІНФОРМАЦІЯ}

Надійшла до редакції/Received: 21.01.2021 p.

Ключові слова: протетична реабілітація верхньої щелепи; бікортикальні імплантати; стратегічна імплантація; негайне функціональне навантаження.

\section{АНОТАЦІЯ}

Резюме. Технологія «Стратегічна імплантація», яка полягає у встановленні бікортикальних імплантатів у кортикальні та стійкі до резорбції ділянки верхньої та нижньої щелеп із їх негайним функціональним навантаженням, є сучасною та добре задокументованою методикою. Однак реставрація однієї зубної дуги, що виконується за наявності у пацієнта на протилежній щелепі власних зубів, коронок чи мостоподібних конструкцій, знімних пластинкових протезів вимагає ретельного підходу до діагностики та планування лікувальних заходів. Так, екструдовані, інтрудовані, дистоповані або навіть сильно нахилені зуби в протилежній дузі повинні бути вирівняні або видалені. Міжзубні проміжки, що існують, необхідно закрити, а знімні протези повинні бути замінені фіксованими ортопедичними конструкціями, щоб досягти стабільних гармонійних контактів та успішного результату імплантації на протилежній щелепі. Часто коронки та мостоподібні конструкції, що існують, повинні бути скориговані відносно протилежної дуги або навіть замінені з метою вирівнювання оклюзійної площини та пристосування щелепи, на якій наявні природні зуби, до протилежної щелепи, на якій буде встановлено імплантати. У дослідженні перераховано низку критеріїв, які необхідно брати до уваги, вирішуючи питання тотальної реабілітації верхньої щелепи 3 використанням бікортикальних імплантатів у протоколі негайного навантаження, а також обгрунтовано доцільність проведення допоміжних втручань на протилежній щелепі відповідно до вимог стратегічної імплантації, невиконання яких є підставою до відмови пацієнту в лікуванні.

Мета дослідження - на основі аналізу фахової літератури та серії клінічних випадків сформулювати вимоги до тотального протезування верхньої щелепи за наявності повністю/частково збереженого зубного ряду на нижній щелепі.

Матеріали і методи. Описано та проаналізовано 4 випадки тотальної реабілітації верхньої щелепи з використанням бікортикальних імплантатів у протоколі негайного навантаження з обгрунтуванням проведення коригуючих втручань на нижній щелепі.

Результати досліджень та їх обговорення. На основі аналізу фахової літератури, власного досвіду та наведених клінічних прикладів сформульовано 7 основних вимог до протезування на бікортикальних імплантатах у протоколі негайного навантаження з огляду на можливість досягнення оптимальних оклюзійних співвідношень: 
- однакова довжина жувальної площини з обох боків;

- однакова ширина жувальної площини 3 обох боків (близько

$8 \mathrm{MM})$;

- уникнення контактів між фронтальними зубами верхньої і нижньої щелеп під час оклюзії та жування;

- симетрична крива Шпеє з обох боків;

- ідентичний функціональний жувальний кут Планаса 3 обох боків (цей аспект включає довжину та положення горбків, які спрямовують жувальний рух);

- паралельність або близькість жувальної площини до горизонталі Кемпера;

- видалення всіх зубів мудрості.

Обгрунтовано доцільність проведення коригуючих операцій/маніпуляцій на нижній щелепі у випадку виготовлення верхньощелепної циркулярної мостоподібної конструкції на бікортикальних імплантатах у протоколі негайного навантаження.

Висновки. На відміну від протезування на традиційних двоетапних остеоінтегрованих імплантатах, вимоги до тотальної протетичної реабілітації щелеп на бікортикальних імплантатах згідно 3 концепцією «Стратегічна імплантація» $є$ набагато суворішими. 3 іншого боку, ці вимоги на сьогодні зрозумілі, прийнятні, логічні й чітко визначені. Довгостроковий успіх реабілітації залежить не лише від ретельного дотримання хірургічного протоколу бікортикальної імплантації, але й від адекватного протезування з урахуванням дентального статусу антагонуючої щелепи.

Вступ. Технологія «Стратегічна імплантація», яка полягає у встановленні бікортикальних імплантатів у кортикальні та стійкі до резорбції ділянки верхньої та нижньої щелеп 3 їх негайним функціональним навантаженням, є сучасною та добре задокументованою методикою [1, 3, 6, 7]. Однак реставрація однієї зубної дуги, що виконується за наявності у пацієнта на протилежній щелепі власних зубів, коронок чи мостоподібних конструкцій, знімних пластинкових протезів вимагає ретельного підходу до діагностики та планування лікувальних заходів з огляду на досягнення адекватних оклюзійних співвідношень.

Упродовж життя, особливо у пацієнтів 3 однобічним типом жування, просторове розташування зубів змінюється унаслідок елонгації чи інтрузії, нахилу зубів, їх зміщення услід за атрофованою кістковою тканиною у напрямку від оклюзійної площини. Щоб забезпечити стабільність жування, на кожній щелепі має бути достатня кількість правильно розташованих і стабільних зубів, а їх оклюзійні поверхні повинні сприяти оптимальному функціонуванню. Необхідно пам'ятати, що природний зубний ряд (без реставрації) має тенденцію до прогресивного стирання упродовж усього життя, поки не буде досягнуто оптимальної оклюзії, що постійно впливає на функціональний жувальний кут Планаca (Angle Fonctionelle de Mastication de Planas, AFMP), який у нормі забезпечує зрівноважене, симетричне, білатеральне жування [8]. Незважаючи на те, що за допомогою сучасних реставраційних технологій стан та кількість зубів у порожнині рота можна належним чином підтримувати упродовж десятиліть, багато пацієнтів дуже рано втрачають можливість рівномірного та двобічного жування. Втрата будь-якого 3 молярів, наприклад призводить до порушення або унеможливлення симетричного жування, а втрата кількох молярів і премолярів зумовлює переміщення жувального навантаження на передні зуби, які на функціональну активацію реагують елонгацією.

Відтак екструдовані, інтрудовані, дистоповані або навіть сильно нахилені зуби в протилежній дузі повинні бути вирівняні або видалені. Міжзубні проміжки, що існують, необхідно закрити, а знімні протези повинні бути замінені фіксованими ортопедичними конструкціями, щоб досягти стабільних гармонійних контактів та успішного результату імплантації на протилежній щелепі. Часто коронки та мостоподібні конструкції, що існують, повинні бути скориговані відносно протилежної дуги або навіть замінені з метою 
вирівнювання оклюзійної площини та пристосування щелепи, на якій наявні природні зуби, до протилежної щелепи, на якій буде встановлено імплантати [2, 5].

Якщо для традиційної двоетапної імплантації, яка грунтується на принципі остеоінтеграції імплантатів та відтермінованого навантаження, такі додаткові маніпуляції не $є$ обов'язковими, то у випадку бікортикальної імплантації, яка передбачає введення імплантатів у кортикальні відділи щелеп за протоколом остеофіксації з їх негайним (в межах 3-4 діб) навантаженням, лікування може втратити частину своєї дуже високої передбачуваності.

$\mathrm{y}$ щоденній клінічній роботі ми часто зустрічаємося з пацієнтами, які вимагають імплантації лише на одній щелепі. Навіть якщо на протилежній щелепі наявні не усі зуби, вони припускають, часто керуючись економічними міркуваннями, що розміщення імплантатів та протезування лише однієї щелепи $€$ достатнім для вирішення їх проблеми.

У цій статті перераховано низку критеріїв, які необхідно брати до уваги, вирішуючи питання тотальної реабілітації верхньої щелепи 3 використанням бікортикальних імплантатів у протоколі негайного навантаження, а також обгрунтовано доцільність проведення допоміжних втручань на протилежній щелепі відповідно до вимог стратегічної імплантації, невиконання яких є підставою до відмови пацієнту в лікуванні.

Метою дослідження було на основі аналізу фахової літератури та серії клінічних випадків сформулювати вимоги до тотального протезування верхньої щелепи за наявності повністю/частково збереженого зубного ряду на нижній щелепі.

Матеріали і методи. Описано та проаналізовано 4 випадки тотальної реабілітації верхньої щелепи з використанням бікортикальних імплантатів у протоколі негайного навантаження 3 обгрунтуванням проведення коригуючих втручань на нижній щелепі. Оскільки вказана стаття стосується лише аспекту створення стабільного та двобічного жування протезними конструкціями, фіксованими на імплантатах, детальна інформація щодо обстежених пацієнтів (стать, вік, анамнестичні відомості, супутня патологія, шкідливі звички тощо) не має принципового значення, а відтак - виключена.

Результати досліджень та їх обговорення. У 2011 р. A. Ihde та S. Ihde [2] сформулювали перелік 7-ми основних вимог до протезування на бікортикальних імплантатах у протоколі негайного навантаження:

- однакова довжина жувальної площини 3 обох боків;

- однакова ширина жувальної площини 3 обох боків (близько 8 мм);

- уникнення контактів між фронтальними зубами верхньої і нижньої щелеп під час оклюзії та жування;

- симетрична крива Шпеє з обох боків;

- ідентичний функціональний жувальний кут Планаса з обох боків (цей аспект включає довжину та положення горбків, які спрямовують жувальний рух);

- паралельність або близькість жувальної площини до горизонталі Кемпера;

- видалення всіх зубів мудрості.

Пізніше, у 2020 р. A. Ihde та S. Ihde [5] дещо уточнили вимогу щодо площин прикусу 3 обох боків щелеп, ввівши, зокрема, поняття «передньо-задньої площини прикусу за Іде» (Anterior-posterior planes of bite of Ihde, APPI), яке включає зміни у вертикальному положенні зубів, а також зміни площини прикусу, створені нахилом зубів, i, по суті, замінює необхідність встановлення "нормальної» кривої Шпеє. Концепція авторів пояснює, чому двобічний ідентичний АРPI принципово необхідний для адекватної жувальної функції зубних рядів, у яких відсутні будь-які фронтальні оклюзійні контакти (наприклад, за умов протезування на бікортикальних імплантатах), тоді як пацієнтам із фронтальними оклюзійними контактами на власних зубах вдається успішно жувати, навіть якщо на одному боці щелепи видно надто акцентовану криву Шпеє, а на іншому вона може бути взагалі оберненою. Більше того, якщо рівний функціональний жувальний кут Планаса вказує на напрямок двобічного ідентичного режиму жування, АРPI описує можливість позиціонування обох скронево-нижньощелепних суглобів (СНЩС) одночасно в положенні функціонального спокою.

Обгрунтування зазначених вище вимог полягає у наступному:

- якщо у пацієнтів виявляються неоднакові за довжиною або шириною жувальні поверхні або існує різниця в кількості жувальних поверхонь (наприклад, у зв'язку з наявністю зубних проміжків), вони, як правило, зумовлюють більш або менш виражений однобічний тип жування; 
- якщо функціональний жувальний кут Планаса не є однаковим справа і зліва, однобічне жування буде розвиватися з боку з меншим кутом. На боці, де функціональний жувальний кут Планаса гостріший, активність жування буде меншою, і зуби матимуть тенденцію до елонгації;

- якщо криві Шпеє або APPI не однакові 3 обох боків, двобічне жування, швидше за все, не відбудеться;

- зуби мудрості вважаються джерелом нестабільності у перспективі, оскільки (особливо після видалення всіх інших зубів) вони можуть мігрувати. Зуби мудрості можуть прорізатися, або змінювати своє просторове положення, і це змінюватиме морфологію кістки в ділянці кута нижньої щелепи. Частково або повністю ретиновані нижні зуби мудрості змінюватимуть напрямки остеонів, і це призводитиме до змін у розподілі щільності кістки порівняно з повністю беззубими щелепами. Все це перешкоджає стабільності імплантата в кістковій тканині;

- якщо площина прикусу не є паралельною до площини Кемпера, нижньощелепний і верхньощелепний зубний ряд співвідноситимуться під кутом, і закриття рота супроводжуватиметься дислокацією мостоподібних конструкцій на кожній щелепі в передньому або задньому напрямку. Передньо-задня рухомість протезних конструкцій, що виникає унаслідок цього, важко піддається лікуванню, що неприйнятно для протоколів негайного завантаження.

Всі вищезгадані функціональні порушення можуть призвести до ситуації, коли імплантати на жувальному боці можуть стати рухомими унаслідок надмірного навантаження кістки. Інші імплантати, що не беруть участі у жуванні, можуть теж стати рухомими, оскільки вони опиняються в зоні функціонального натягу кістки, в якій вміст мінеральних речовин швидко знижується (остеопороз за відсутності навантаження). Цього варто уникати, i єдиним способом зробити це є створення правильної жувальної площини, яка автоматично сприятиме двобічному рівномірному жуванню на бічних зубах.

Важливо також розуміти, що досвід використання традиційних крестальних зубних імплантатів, розроблених для концепції «остеоінтеграції», не допомагає зрозуміти особливості негайно навантажених бікортикальних імплантатів. Надмірне навантаження остеоінтегрованих імплантатів може при- звести до перелому протезних конструкцій, гвинтів або абатментів, а в деяких випадках і до переломів самого тіла імплантата. Однак в остеоінтегрованих імплантатах майже ніколи не виникає рухомості унаслідок надмірного навантаження. У випадку бікортикальних імплантатів, які передають навантаження на 2-гі кортикальні пластинки, навпаки, накопичення мікроушкоджень кортикальної кістки унаслідок надмірного навантаження зумовлюватиме втрату фіксації та рухомість тіла імплантата.

Усі вищезгадані аспекти впливають на формування загального плану лікування, що передбачає не лише встановлення імплантатів на одній із щелеп з їх негайним навантаженням, але й низку коригуючих операцій/маніпуляцій на протилежній щелепі й наступні приклади це ілюструють.

Клінічний випадок 1 (рис. 1а, 1б)

Пацієнт К. потребує тотальної реабілітації верхньої щелепи (рис. 1а). Консоль, прикріплений до двох премолярів у 3-му квадранті, не забезпечує належної жувальної функції.

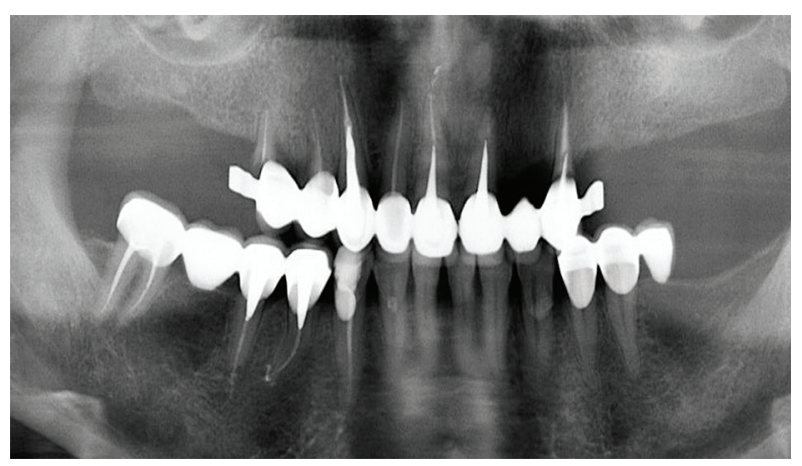

Puc. 1a. Передопераційна ортопантомограма пацієнта К. Часткова адентія верхньої та нижньої щелеп.

Для того, щоб забезпечити рівномірне двобічне жування, було видалено консольну конструкцію у проєкції 36 зуба та встановлено 3 стабільні імплантати, що дозволило створити стійку жувальну та оклюзійну поверхню 36 зуба на імплантатах (рис. 1б). Верхній мостоподібний протез забезпечує функціональну й однакову за довжиною та шириною жувальну площину в межах премолярів та молярів. Зуб 47 залишається нефункціональним, оскільки на верхній щелепі відсутній антагоніст. Якщо прогноз мостоподібного протеза в 4-му квадранті є сумнівним, усі 3 опорні зуби необхідно видалити і замінити сегментарним мостоподібним протезом на 4 або 5 бікортикальних імплантатах. 


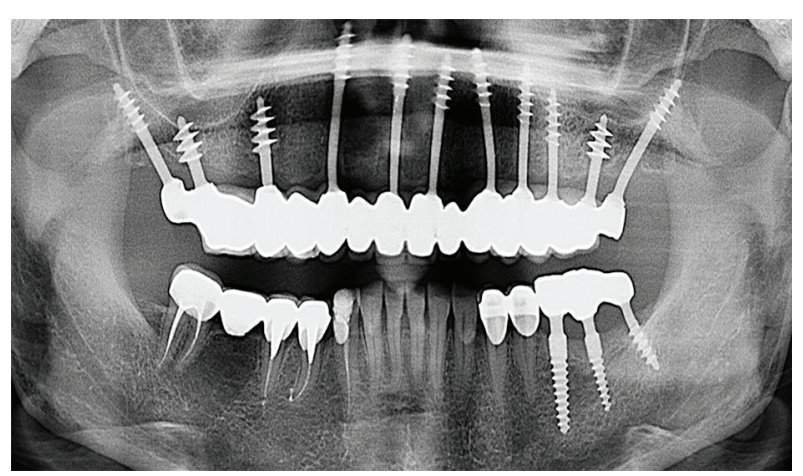

Puc. 1б. Післяопераційна ортопантомограма пацієнта К. із встановленими імплантатами та протезними конструкціями.

Клінічний випадок 2 (рис. 2а, 2б)

Пацієнт С. вимагає тотальної реабілітації беззубої та атрофованої верхньої щелепи без значних змін у нижній (рис. 2а).

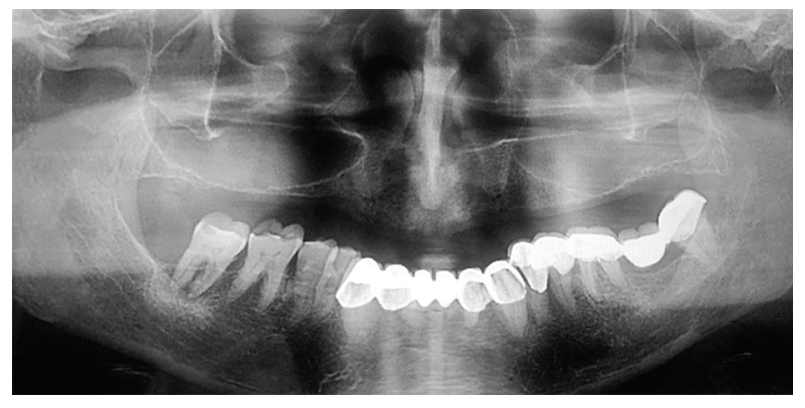

Puc. 2a. Передопераційна ортопантомограма пацієнта С. Повна адентія та атрофія верхньої щелепи.

Перед протезуванням верхньої щелепи проведено наступні корекції на нижній зубній дузі: видалено зуб 37, пришліфовано лінгвальні нефункціональні горбки на правих нижніх молярах (рис. 2б). Зуб 47 залишився без функціонального навантаження, його варто контролювати на предмет елонгації, і у майбутньому видалити. Пізніше проведено імплантацію на верхній щелепі та виготовлення мостоподібного протеза в межах 16-26 зубів. Той факт, що передні зуби не досягають площини прикусу, не важливий, оскільки оклюзійний та

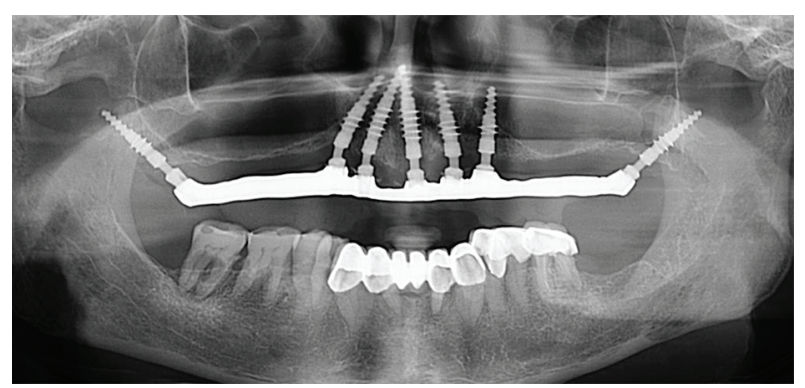

Puc. 2б. Післяопераційна ортопантомограма пацієнта С. із встановленими імплантатами та протезною конструкцією. жувальний контакти між верхніми та нижніми передніми зубами в бікортикальній імплантації заборонені. В результаті пацієнтові було встановлено конструкцію, що дала можливість жування на довжині 2 премолярів та 1 моляра. За досвідом цього більш ніж достатньо.

\section{Клінічний випадок 3 (рис. 3а, 3б)}

Пацієнт Р., який упродовж 28 років користувався знімними конструкціями на верхній та нижній щелепах, звернувся з проханням реабілітації беззубої верхньої щелепи за допомогою імплантатів (рис. За). Як видно з ортопантомограми, спостерігається суттєве зубоальвеолярне видовження у фронтальному відділі нижньої щелепи. Незважаючи на те, що клінічно та рентгенологічно зуби 34,33 , $32,31,42,43$ виглядають стійкими та без ознак періодонтального ураження, пацієнтові пояснено необхідність видалення вказаних зубів задля забезпечення нормального оклюзійного співвідношення при протезуванні на імплантатах та уникнення переднього типу жування у майбутньому, а відтак - неможливість проводити реабілітацію верхньої щелепи без одномоментних коригуючих втручань на нижній щелепі. Більше того, ситуація ускладнювалась наявністю лезоподібного альвеолярного гребеня на верхній щелепі, що унеможливлювало застосування відомої методики «Все на 4».

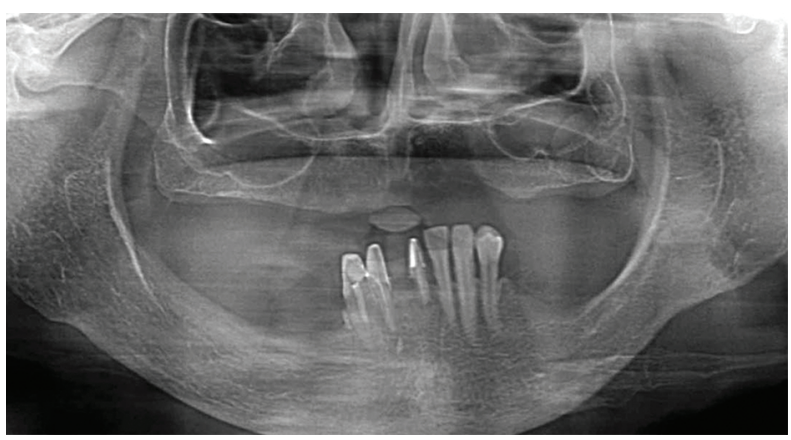

Puc. 3a. Передопераційна ортопантомограма пацієнта Р. Повна адентія верхньої щелепи та часткова адентія нижньої щелепи.

у часі операційного втручання проведено множинне видалення зубів нижньої щелепи, вертикальну редукцію альвеолярного гребеня нижньої щелепи, встановлено 10 бікортикальних імплантатів на верхній щелепі та 8 - на нижній щелепі за технологією «Стратегічна імплантація», що дозволило відновити не лише функціональний, але й естетичний статус щелепно-лицевої ділянки (рис. 3б). У вказаному випадку імплантація та протезування 
обох щелеп одночасно дозволили, з технічної точки зору створити оптимальну жувальну площину з урахуванням усіх вищезазначених вимог.

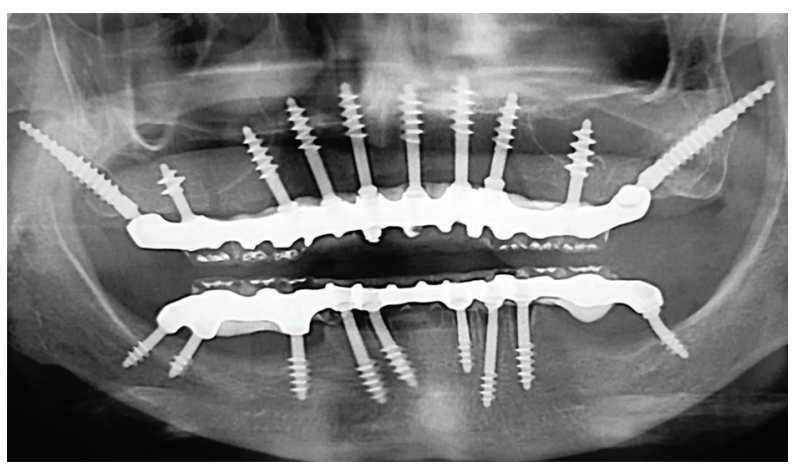

Puc. 3б. Післяопераційна ортопантомограма пацієнта Р. із встановленими імплантатами та протезними конструкціями.

\section{Клінічний випадок 4 (рис. 4а, 4б)}

Пацієнт Н. звернувся з проханням тотальної реабілітації верхньої щелепи (рис. 4а). Очевидно, що двоетапний імплантат у другому квадранті потребує видалення. Сегментарний міст на кортикальних імплантатах у третьому квадранті встановлений кілька років тому. Проте чи можливо зробити адекватне протезування верхньої щелепи без додаткових втручань на нижній щелепі? Як чітко видно 3 передопераційної ортопантомограми, нижня передня група зубів значно витягнута порівняно з обома бічними сегментами нижньої щелепи. Технічно можна виготовити циркулярний міст на бікортикальних імплантатах на верхній щелепі, однак технологія «Стратегічна імплантація» вимагає уникати статичних та жувальних контактів між фронтальними групами. У ситуації, яка проілюстрована на рис. 4а, цього досягнути неможливо. Тому пацієнт був проінформований, що реабілітація верхньої щелепи без видалення нижньої передньої групи зубів проводитись не може.

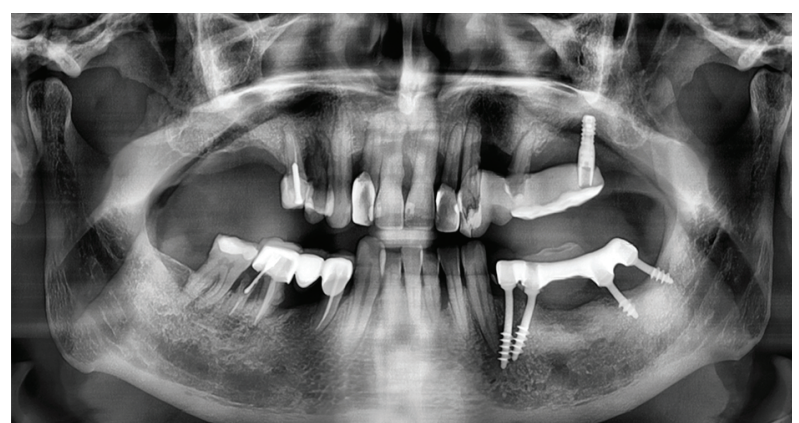

Puc. 4a. Передопераційна ортопантомограма пацієнта Н. Часткова адентія верхньої щелепи.
Для реабілітації пацієнта у цьому випадку був обраний комплексний підхід до лікування: після видалення всіх зубів, що залишились на обох щелепах, проведено вертикальну редукцію альвеолярних відростків і введено бікортикальні імплантати згідно з гайдлайном Міжнародного фонду імплантологів (www. implantfoundation.org) (рис. 4б). Оскільки зуб 33 тепер було видалено (і стратегічне положення було звільнено), з'явилась можливість переставити один бікортикальний імплантат із ділянки 34 у ділянку 33, і тим самим розмістити його у стратегічному положенні й зафіксувати. У вказаному випадку альтернативи множинному видаленню зубів нижньої щелепи не було, тому що залишення нижньої фронтальної групи спричинилося б до розвитку передньої моделі жування. Така схема жування зумовлює постійний вплив екструзивних сил на найбільш дистальні імплантати на верхній щелепі, що створює небезпеку для їх стабільності.

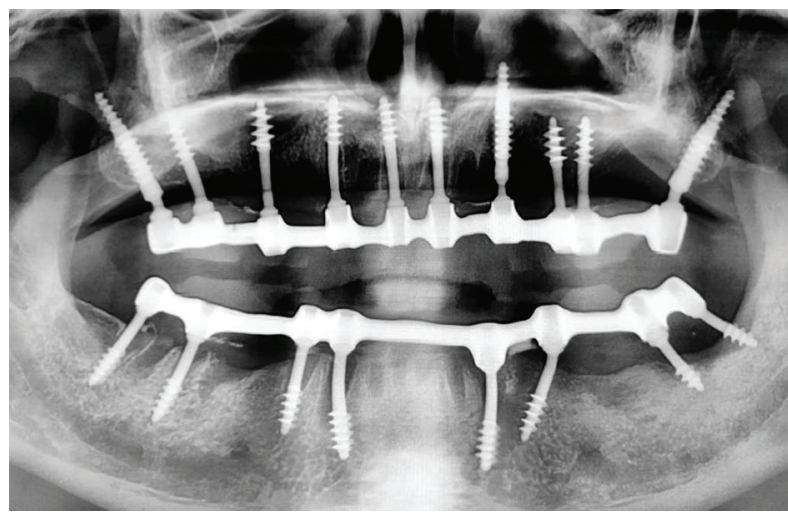

Puc. 4б. Післяопераційна ортопантомограма пацієнта Н. із встановленими імплантатами та протезними конструкціями.

Оскільки верхня щелепа містить менше кортикальної речовини, ніж нижня, кількість імплантатів, що використовується для тотальної реабілітації верхньої щелепи, буде завжди більшою. Зазвичай, для реабілітації верхньої щелепи в загоєну кістку або свіжі післяекстракційні лунки встановлюють 10-14 бікортикальних гладких гвинтових імплантатів за технологією «Стратегічна імплантація». Більше того, на відміну від відомих методик «Все на 4» і «Все на 6», які обмежуються введенням імплантатів у фронтальному відділі верхньої щелепи (допереду від верхньощелепних синусів) і створюють великі навантаження на кістку та імплантати завдяки дистальним консольним елементам, необхідною умовою технології «Стратегічна імплантація» є забез- 
печення потужних дистальних опор для майбутньої верхньощелепної протезної конструкції у вигляді так званої горбово-крилоподібної імплантації, яка передбачає введення імплантатів у сильно мінералізовані та кортикалізовані відділи крилоподібного відростка основної кістки, що дозволяє не лише уникнути додаткових хірургічних втручань, спрямованих на збільшення об'єму кісткової тканини в дистальних сегментах верхньої щелепи, але й забезпечити сценарій природної передачі жувального навантаження уздовж горбово-крилоподібного контрфорсу $[1,9,10]$.

На сьогодні доведено [1, 3, 6, 7], що протетична реабілітація щелеп 3 використанням технології «Страгегічна імплантація» $€$ дуже успішною за умов суворого дотримання стандартів протезування при негайному функціональному навантаженні, коли всі імплантати обов'язково шинуються жорстким металевим каркасом і зазнають прогресивного навантаження 3 найближих (2-3 доби) термінів після ïх встановлення, що є основним принципом загальної травматології.

У випадках, коли протезування на кортикальних імплантатах передбачається лише на верхній щелепі, а нижня щелепа містить природні зуби та/чи мостоподібні конструкції, фіксовані на них, необхідна ретельна критична оцінка придатності нижнього зубного ряду як протилежного до верхньощелепної циркулярної мостоподібної конструкції на бікортикальних імплантатах у протоколі негайного навантаження. Дистоповані, екструдовані, інтрудовані або нахилені зуби (або протезні конструкції) в протилежній дузі повинні бути виправлені, щоб досягти стабільних гармонійних контактів і довгострокового успіху. Нижні часткові знімні протези (навіть якщо вони сконструйовані симетрично) не рекомендується використовувати, оскільки шанси на те, що пацієнти регулярно використовують ïх для жування, низькі. Більше того, шанси на те, що пацієнти зі знімними конструкціями на нижній щелепі виконують рівномірні двобічні латерально орієнтовані жувальні рухи, ще нижчі. Хоча нижньощелепний зубний ряд із встановленим частковим протезом можна вважати «повним», заміна усіх знімних часткових протезів на нижній щелепі є, на наш погляд, необхідною допоміжною терапією за умови тотального протезування верхньої щелепи з використанням бікортикальних імплантатів у протоколі негайного навантаження.
Окрім первинної стабільності імплантатів, яка досягається за допомогою кортикального анкоражу, оптимальний біомеханічний розподіл навантаження на протезну конструкцію має першочергове значення. Для досягнення такого розподілу необхідно створити умови для двобічного рівномірного жування. Безперечно, що керування оклюзією набагато простіше у випадках одномоментної тотальної реабілітації обох щелеп, порівняно 3 реабілітацією однієї дуги або сегментарними конструкціями, оскільки дозволяє створити оклюзійну та функціональну ситуацію відповідно до вимог, не обмежуючись жодними зубами, розташованими в несприятливих просторових положеннях.

Технологія «Стратегічна імплантація» включає поняття лінгвалізованої оклюзії, оскільки відцентрова атрофія нижньої щелепи у поєднанні з доцентровою атрофією верхньої щелепи повинна бути компенсована. Якщо адекватно виконати цю умову, сили, що діють на кістку, будуть в основному стискаючими (інтрузивними), що дозволятиме уникнути несприятливих зон натягу.

Зрозуміло, що зберегти вищезгадані результати початкової фази лікування упродовж усього життя пацієнта буде неможливим, оскільки клінічна ситуація постійно змінюватиметься під впливом багатьох чинників i потребуватиме періодичних контрольних оглядів та корекцій. Так, поступове стирання протезних конструкцій або природних зубів призводитиме до наближення фронтальної групи зубів, що вимагатиме необхідності збільшення вертикального розміру. На металево-композитних мостоподібних конструкціях це можна зробити, додаючи шар композиту на оклюзійних поверхнях. Якщо ж мостоподібна конструкція на імплантатах встановлена лише на одній щелепі, з метою попередження стирання рекомендується використання метало-керамічних або цирконієвих протезів, а не конструкцій, виготовлених з акрилу або композиту. Також нерівномірним стиранням будуть проявлятись односторонні моделі жування, які можуть розвинутися в будь-який час і потребуватимуть корекції.

Якщо реабілітації зазнає лише верхня щелепа, то нижній регулярно буде необхідна корекція. Пацієнти повинні бути поінформовані про те, що такі корекції будуть проведені до початку лікування, а також в процесі лікування і пізніше - у віддалені після імп- 
лантації терміни, і вони повинні погодитися на ці коригування. Якщо зуби екструдовані, ix потрібно пришліфовувати, може рекомендуватись також ендодонтичне лікування або видалення окремих зубів. У випадках наявності зубощелепних деформацій 2-го класу за Енглем спостерігається зміщення нижньої щелепи у дистальному напрямку, що створює великий сагітальний проміжок між верхніми та нижніми передніми зубами. Нерідко в таких випадках також нижній 1-й премоляр втрачає контакт 3 антагоністом. Якби обидві щелепи підлягали реабілітації за допомогою імплантатів, цю невідповідність можна було б компенсувати за допомогою мостоподібних конструкцій. Якщо ж протезування на імплантатах стосується лише верхньої щелепи, тоді як нижня щелепа вузька, на нижньому 1-му премолярі повинна бути встановлена коронка, щоб перемістити щічний горбик вестибулярніше і привести його до оклюзійного контакту, що є обов'язковою умовою для орієнтації нервово-м’язової системи $[4,8]$.

Висновки. На відміну від протезування на традиційних двоетапних остеоінтегрованих імплантатах вимоги до тотальної протетичної реабілітації щелеп на бік кортикальних імплантатах згідно 3 технологією «Стратегічна імплантація» $є$ набагато суворішими. 3 іншого боку, ці вимоги на сьогодні зрозумілі, прийнятні, логічні й чітко визначені $[2,5]$. Якщо потрібна велика кількість корекцій решти зубів та протезування на протилежній нижній щелепі, з пацієнтом необхідно обговорити можливість множинного видалення усіх зубів та встановлення двох циркулярних мостоподібних конструкцій згідно 3 технологією «Стратегічна імплантація», навіть якщо декілька зубів можуть вартувати збереження 3 точки зору класичної стоматології. Технологія «Стратегічна імплантація» дозволяє проводити реабілітацію практично усіх пацієнтів незалежно від існуючої кількості та/чи якості кісткової тканини щелеп та за протоколом негайного навантаження. Водночас, довгостроковий успіх реабілітації залежить не лише від ретельного дотримання хірургічного протоколу бікортикальної імплантації, але й від адекватного протезування з урахуванням дентального статусу антагонуючої щелепи.

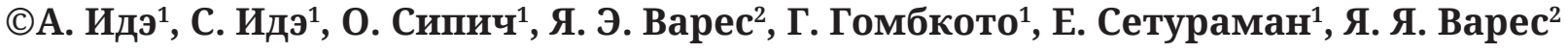 Международный фонд имплантологов, г. Мюнхен, Германия ${ }^{1}$ Львовский национальный медицинский университет имени Данила Галицкого 2 \\ Требования к тотальной протетической реабилитации верхней челюсти за технологией «Стратегическая имплантация» в условиях протокола немедленной нагрузки (описание серии клинических случаев)
}

\begin{abstract}
Резюме. Технология «Стратегическая имплантация», основанная на установке бикортикальных имплантатов в кортикальные и стойкие к резорбции отделы верхней и нижней челюсти с их немедленной функциональной нагрузкой, является современной и хорошо задокументированной методикой. Однако восстановление одной зубной дуги, которое проводится при наличии у пациента на противоположной челюсти собственных зубов, коронок или мостовидных конструкций, съемных пластиночных протезов требует тщательного подхода к диагностике и планированию лечебных мероприятий. Так, экструдированные, интрудированные, дистопированные или даже сильно наклоненные зубы в противоположной дуге должны быть выровнены или удалены. Имеющиеся зубные промежутки следует закрыть, а съемные протезы должны быть заменены фиксированными ортопедическими конструкциями для достижения стабильных гармонических контактов и успешного результата имплантации на противоположной челюсти. Коронки и мостовидные конструкции должны быть скорректированы соответсвенно противоположной дуге или даже заменены с целью выравнивания окклизионной плоскости и припасовки челюсти, на которой имеются естественные зубы, к противоположной челюсти, на которой будут установлены имплантаты. В настоящей статье перечислено ряд критериев, которые следует учитывать при решении вопроса тотальной реабилитации верхней челюсти с использованием бикортикальных имплантатов в протоколе немедленной нагрузки, а также обосновано целесообразность проведения дополнительных вмешательств на противоположной челюсти в соответствии с требованиями стратегической имплантации, невыполнение которых есть основанием к отказу пациенту в лечении.
\end{abstract}


Цель исследования - на основании анализа специальной литературы и серии клинических случаев сформулировать требования к тотальному протезированию верхней челюсти при наличии полностью/частично сохраненного зубного ряда на нижней челюсти.

Материалы и методы. Описано и проанализированно 4 случая тотальной реабилитации верхней челюсти с использованием бикортикальных имплантатов в протоколе немедленной нагрузки с обоснованием проведения корректирующих вмешательств на нижней челюсти.

Результаты исследований и их обсуждение. На основании анализа специальной литературы, собственного опыта и приведенных клинических случаев сформулировано 7 основных требований к протезированию на бикортикальных имплантатах в протоколе немедленной нагрузки с точки зрения возможности достижения оптимальных окклюзионных соотношений:

- одинаковая длина жевательной плоскости с обеих сторон;

- одинаковая ширина жевательной плоскости с обеих сторон (приблизительно 8 мм);

- избегание контактов между фронтальными зубами верхней и нижней челюстей во время окклюзии и жевания;

- симметрическая кривая Шпее с обеих сторон;

- идентичный функциональный жевательный угол Планаса з обеих сторон (этот аспект включает длину и положение бугров, направляющих жевательные движения);

- параллельность или близкость жевательной плоскости к горизонтали Кемпера;

- удаление всех зубов мудрости.

Обоснованно целесообразность проведения коррегирующих операций/манипуляций на нижней челюсти в случае изготовления верхнечелюстной циркулярной мостовидной конструкции на бикортикальных имплантатах в протоколе немедленной нагрузки.

Выводы. В отличии от протезирования на традиционных двухэтапных остеоинтегрированных имплантатах требования к тотальной протетической реабилитации челюстей на бикортикальных имплантатах соответственно с технологией «Стратегическая имплантация» намного строже. С другой стороны, эти требования на сегодня понятны, приемлемы, логические и четко обозначены. Долгосрочный успех реабилитации зависит не только от тщательного соблюдения хирургического протокола бикортикальной имплантации, но и от адекватного протезирования с учетом дентального статуса антагонирующей челюсти.

Ключевые слова: протетическая реабилитация верхней челюсти; бикортикальные имплантаты; стратегическая имплантация; немедленная функциональная нагрузка.

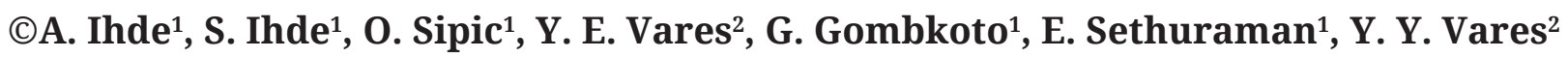 \\ International Implant Foundation, Munich, Germany ${ }^{1}$ \\ Danylo Halytsky Lviv National Medical University ${ }^{2}$
}

\title{
Requrements for total prosthetic maxillary rehabilitation according to Strategic implant technology in immediate loading protocol (case series report)
}

Summary. Strategic Implant technology, which involves the installation of bicortical implants in the cortical and resorption-free areas of the upper and lower jaws with their immediate functional loading, is a modern and well-documented technique. However, the restoration of a single dental arch, performed when the patient has his own teeth, crowns or bridges on the opposite jaw, removable plate dentures requires a careful approach to diagnosis and treatment planning. Thus, extruded, intruded, dystopian or even strongly inclined teeth in the opposite arch must be aligned or removed. Existing interdental spaces should be closed, and removable dentures should be replaced with fixed orthopedic structures to achieve stable harmonious contacts and successful implantation on the opposite jaw. Often existing crowns and bridges must be adjusted relative to the opposite arch or even replaced to align the occlusal plane and adjust the jaw, which has natural teeth, to the opposite jaw, where the implants will be placed.

This article lists a number of criteria that should be taken into account when deciding on the total rehabilitation of the upper jaw with the use of bicortical implants in the protocol of immediate loading, and substantiates the feasibility of supporting interventions on the opposite jaw in accordance with the requirements of Strategic Implant technology.

The aim of the study - to formulate requirements for total prosthetics of the upper jaw in the presence of fully / partially preserved dentition on the lower jaw on the basis of the analysis of professional literature and a series of clinical cases. 
Materials and Methods. 4 cases of total rehabilitation of the upper jaw with the use of bicortical implants in the protocol of immediate loading with the substantiation of corrective interventions on the lower jaw are described and analyzed.

Results and Discussion. Based on the analysis of the professional literature, own experience and clinical examples, 7 main requirements for prosthetics on bicortical implants are formulated in the protocol of immediate loading, given the possibility of achieving optimal occlusal relationship:

- The same length of the masticatory plane on both sides;

- The same width of the masticatory plane on both sides (about $8 \mathrm{~mm}$ );

- Avoid contact between the front teeth of the upper and lower jaws during occlusion and chewing;

- Symmetrical Spee curve on both sides;

- Identical functional chewing angle of Planas on both sides (this aspect includes the length and position of the tubercles that direct the chewing movement);

- Parallelism or proximity of the masticatory plane to the Camper's horizontal;

- Removal of all wisdom teeth.

The expediency of corrective operations / manipulations on the mandible in the case of manufacturing a maxillary circular bridge structure on cortical implants in the protocol of immediate loading is substantiated. Conclusions. Unlike prosthetics on traditional two-stage osseointegrated implants, the requirements for total prosthetic rehabilitation of the jaws on bicortical implants according to the concept of Strategic Implant are much stricter. On the other hand, these requirements are now understandable, acceptable, logical and clearly defined. The long-term success of rehabilitation depends not only on careful adherence to the surgical protocol of bicortical implantation, but also on adequate prosthetics, taking into account the dental status of the antagonizing jaw.

Key words: prosthetic maxillary rehabilitation; bicortical implants; strategic implant; immediate functional loading.

\section{СПИСОК ЛІТЕРАТУРИ}

1. Іде С. Введення у роботу із Стратегічними імплантатами / С. Іде, Я. Е. Варес, А. Іде. - Мюнхен : International Implant Foundation Publishing, 2015. $82 \mathrm{c}$.

2. Идэ С. Секреты базальной имплантологии / С. Идэ, А. Идэ. - Мюнхен : International Implant Foundation Publishing, 2011. -358 c.

3. Gaur V. Evaluation of the Success of Strategic Implant Placement for Imeediate Loading Prosthesis in Edentulous Cases / V. Gaur, A. G. Doshi, A. K. S. Bengani // Dentistry. - 2020. - Vol. 10 (565). - P. 1-8.

4. Hanau R. L. Occlusal Changes in Centric Relation / R. L. Hanau / J. Amer. Dent. Assoc. - 1929. - Vol. 16 (10). - P. 1903-1915.

5. Ihde S. Cookbook Mastication / S. Ihde, A. Ihde. - 4th ed. rev. - Munich : International Implant Foundation publishing, 2020. - 92 p.

\section{REFERENCES}

1. Ihde, S., Vares, Ya., \& Ihde, A. (2015). Vvedennia u robotu iz Stratehichnymy implantamy [Introduction to Strategic implants]. Munich: International Implant Foundation Publishing [in Ukrainian].

2. Ihde, S., \& Ihde, A. (2011). Sekrety bazalnoi implantologii [Secrets of bazal implantology]. Munich: International Implant Foundation Publishing [in Russian].

3. Gaur, V., Doshi, A.G., \& Bengani, A.K.S. (2020). Evaluation of the success of strategic implant placement for imeediate loading prosthesis in edentulous cases. Dentistry, 10 (565), 1-8.
6. Lazarov A. Immediate functional loading: Results for the concept of the Strategic implant / A. Lazarov // Ann. Maxillofac. Surg. - 2019. - Vol. 9. - P. 78-88.

7. Pałka L. R. Immediately loaded bicortical implants inserted in fresh extraction and healed sites in patients with and without a history of periodontal disease / L. R. Palka, A. Lazarov // Ann. Maxillofac. Surg. - 2019 Vol. 9. - P. 371-378.

8. Planas P. La rehabilitation neuro-occlusale / P. Planas. - Paris : Masson, 1997. - 290 p.

9. Scortecci G. Basal Implantology / G. Scortecci. - Cham : Springer Nature, 2019. - 398 p.

10. Vares Y. Tubero-pterygoid implant as means of rehabilitation of patient with adentia and atrophy of distal maxillary aspect. Case report / Y. Vares, Y. Gudzan // Inter. J. Curr. Res. - 2019. - Vol. 11 (2). - P. 1161-1163.
4. Hanau, R.L. (1929). Occlusal changes in centric relation. J. Amer. Dent. Assoc., 16 (10), 1903-1915.

5. Ihde, S., \& Ihde, A. (2020). Cookbook Mastication. $4^{\text {th }}$ ed. rev. Munich: International Implant Foundation publishing.

6. Lazarov, A. (2019). Immediate functional loading: Results for the concept of the Strategic implant. Ann. Maxillofac. Surg., 9, 78-88.

7. Pałka, L.R., \& Lazarov, A. (2019). Immediately loaded bicortical implants inserted in fresh extraction and healed sites in patients with and without a history of 


\section{Хірургічна стоматологія}

periodontal disease. Ann. Maxillofac. Surg., 9, 371-378. 8. Planas, P. (1997). La rehabilitation neuro-occlusale. Paris: Masson.

9. Scortecci, G. (2019). Basal implantology. Cham Springer Nature.
10. Vares, Y., \& Gudzan, Y. (2019). Tubero-pterygoid implant as means of rehabilitation of patient with adentia and atrophy of distal maxillary aspect. Case report. Inter. J. Curr. Res., 11 (2), 1161-1163. 